\title{
LETTERS
}

\section{Response to: "Snowfall and myocardial infarction. What is the effect of barometric pressure?"}

In a recent letter to CMAJ, Hernández-Garduño raised the possibility that barometric pressure contributes to the association between snowfall and myocardial infarction (MI). ${ }^{1}$ We confirm that in sensitivity analyses, adjustment for barometric pressure $(\mathrm{kPa})$ had no impact on the association between snowfall and MI.

Compared with $0 \mathrm{~cm}, 20 \mathrm{~cm}$ of snow was associated with an odds ratio (OR) of 1.15 for admission to hospital (95\% confidence interval $[\mathrm{Cl}] 1.09-1.21)$ and an OR of 1.30 for death $(95 \% \mathrm{Cl} 1.20-1.40)$ the following day in men, with adjustment for splines for both barometric pressure and change in pressure. In addition, we found no association between barometric pressure and $\mathrm{MI}$ in models adjusted for snowfall and temperature.

We cannot be certain why previous studies found associations between barometric pressure and cardiovascular outcomes, but suboptimal study designs may have been used. ${ }^{2-4}$ The studies were all based on aggregate data, including means of daily morbidity rates ${ }^{2}$ or daily incidence. ${ }^{3,4}$ Ecologic analyses of aggregate data may be subject to bias and inadequate control for individual-level patient characteristics. ${ }^{5}$ We encourage future research of the potential impact of barometric pressure and cardiovascular outcomes with more optimal study designs.

\section{Nathalie Auger MD MSc}

Centre de recherche du centre hospitalier de l'Universite de Montréal, and Institut national de santé publique du Québec, Montréal, Que.

\section{Brian J. Potter MDCM MSC}

Centre de recherche du centre hospitalier de l'Université de Montréal, and Division of Cardiology, Department of Medicine, Centre hospitalier de l'Université de Montréal, Montréal, Que.

\section{Audrey Smargiassi PhD}

Institut national de santé publique du Québec, and Institut national de santé publique du Québec, and Department of Occupational and Environmental Health, School of Public Health, Université de Montréal, Montréal, Que.

\section{Marianne Bilodeau-Bertrand MSc}

Centre de recherche du centre hospitalier de l'Université de Montréal, and Institut national de santé publique du Quebec, Montréal, Que.

\section{Tom Kosatsky MD MPH}

National Collaborating Centre for

Environmental Health, British Columbia

Centre for Disease Control, Vancouver, BC

Cite as: CMAJ 2017 April 18;189:E577. doi: $10.1503 / \mathrm{cmaj} .732948$

\section{References}

1. Hernández-Garduño E. Snowfall and myocardial infarction. What is the effect of barometric pressure? [letter] CMAJ 2017;189:E576.

2. Danet S, Richard F, Montaye M, et al. Unhealthy effects of atmospheric temperature and pressure on the occurrence of myocardial infarction and coronary deaths. A 10-year survey: the LilleWorld Health Organization MONICA project (Monitoring trends and determinants in cardiovascular disease). Circulation 1999;100:E1-7.

3. Goerre S, Egli C, Gerber S, et al. Impact of weather and climate on the incidence of acute coronary syndromes. Int J Cardiol 2007;118:36-40.

4. Ohlson CG, Bodin L, Bryngelsson IL, et al. Winter weather conditions and myocardial infarctions. Scand J Soc Med 1991;19:20-5.

5. Webster TF. Bias magnification in ecologic studies: a methodological investigation. Environ Health 2007;6:17.

Competing interests: None declared. 